\title{
Correction to: Iron sulfide formation on root surfaces controlled by the life cycle of wild rice (Zizania palustris)
}

\author{
Sophia LaFond-Hudson (D) Nathan W. Johnson · John Pastor • \\ Brad Dewey
}

Published online: 4 October 2018

(C) Springer Nature Switzerland AG 2018

\section{Correction to: Biogeochemistry \\ https://doi.org/10.1007/s10533-018-0491-5}

In the online and printed version of this article the Acknowledgements section omitted some information. Additionally, Figures 3 and 4 did not contain proper background shading to depict the life stages. The correct Figs. 3 and 4 and Acknowledgements section are provided.

The original article can be found online at https://doi.org/10.1007/s10533-018-0491-5.

S. LaFond-Hudson $(\bowtie)$

Water Resource Science, University of Minnesota Duluth,

Duluth, MN 55812, USA

e-mail: lafo0062@d.umn.edu

N. W. Johnson

Department of Civil Engineering, University of

Minnesota Duluth, Duluth, MN 55812, USA

e-mail: nwjohnso@d.umn.edu

J. Pastor · B. Dewey

Department of Biology, University of Minnesota Duluth,

Duluth, MN 55812, USA

e-mail: jpastor@d.umn.edu

B. Dewey

e-mail: bdewey@d.umn.edu
Acknowledgements This work was prepared by Sophie LaFond-Hudson, Nathan Johnson, and John Pastor using federal funds under award NA14OAR4170080 from Minnesota Sea Grant, National Sea Grant College Program, National Oceanic and Atmospheric Administration, U.S. Department of Commerce. The statements, findings, conclusions, and recommendations are those of the author(s) and do not necessarily reflect the views of NOAA, the Sea Grant College Program, or the U.S. Department of Commerce. Additional funding was provided by the Fond du Lac Band of Lake Superior Chippewa. Sediment was provided from a wild rice lake on the Fond du Lac Reservation. 
Fig. 3 Seasonal variations in iron speciation and AVS for a sulfate-amended and b unamended conditions on root surfaces. The gray bars in panels $\mathbf{a}$ and $\mathbf{b}$ indicate ferric iron and the black bars represent ferrous iron. Root AVS concentrations are shown by gray diamonds. The shaded background represents the seed production life stage. Error bars are omitted for clarity, but standard deviation is on average $33 \%$ of the mean

Fig. 4 Plant response in sulfate-amended and unamended conditions; a seed count. b total seed mass. $\mathbf{c}$ total mass of nitrogen in seeds, $\mathbf{d}$ total plant nitrogen, calculated by summing nitrogen from seeds, stems, and leaves. Diamonds represent plants grown in surface water with $3.1 \mathrm{mM}$ sulfate and squares represent unamended plants. The shaded background represents the seed production life stage. Error bars represent one standard deviation of four replicates
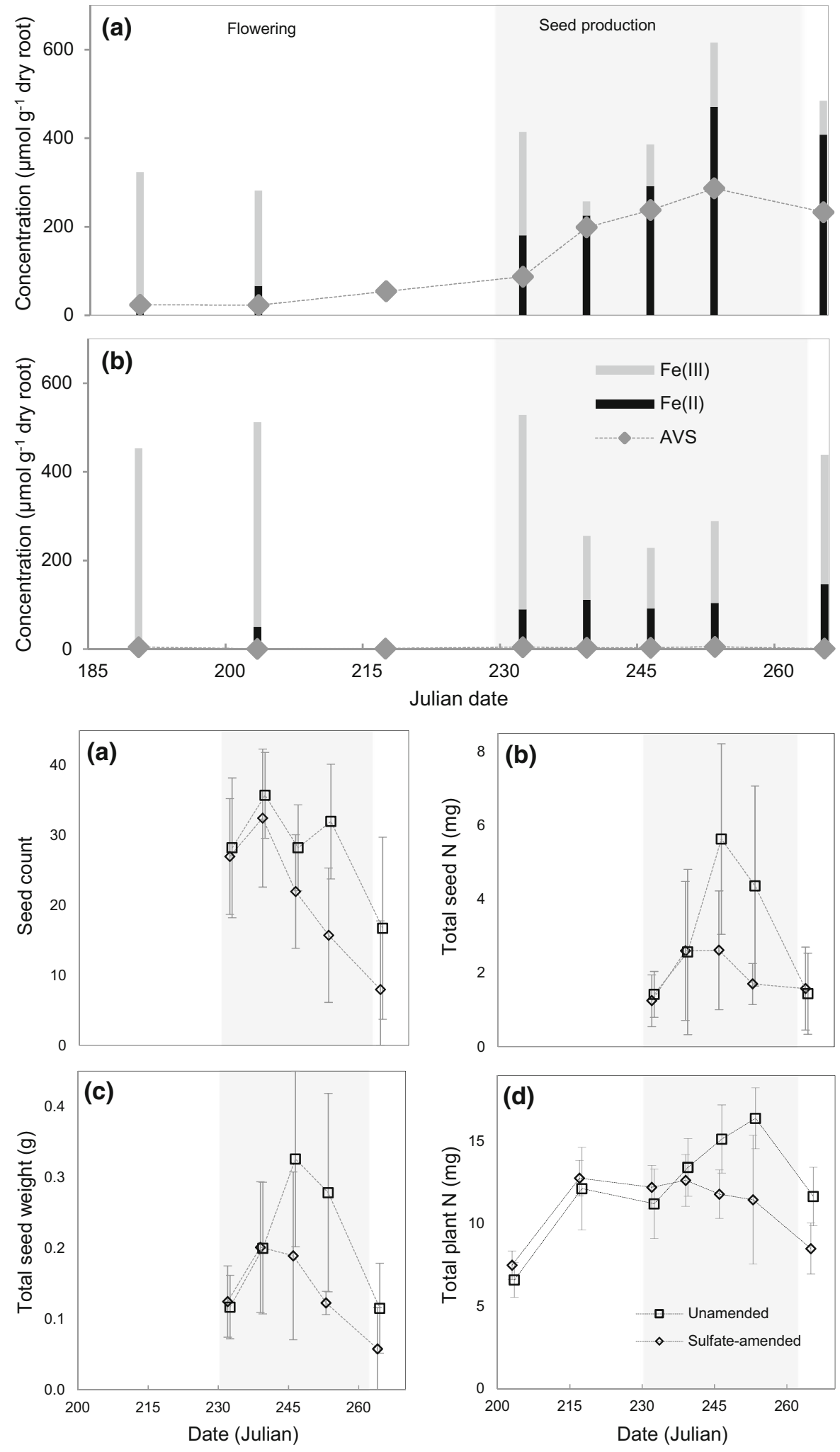